\title{
Does coagulopathy, anticoagulant or antithrombotic therapy matter in incisional hernia repair? Data from the Herniamed Registry
}

\author{
Ralph F. Staerkle ${ }^{1} \cdot$ Henry Hoffmann ${ }^{1} \cdot$ Ferdinand Köckerling $^{2} \cdot$ Daniela Adolf $^{3} \cdot$ Reinhard Bittner $^{4} \cdot$ Philipp Kirchhoff $^{1}$
}

Received: 19 October 2017 / Accepted: 23 February 2018 / Published online: 28 February 2018

(c) The Author(s) 2018. This article is an open access publication

\begin{abstract}
Background A considerable number of patients undergoing incisional hernia repair are on anticoagulant or antiplatelet therapy or have existing coagulopathy which may put them at higher risk for postoperative bleeding complications. Data about the optimal treatment of these patients are sparse. This analysis attempts to determine the rate of postoperative bleeding complications following incisional hernia repair and the consecutive rate of reoperation among patients with coagulopathy or receiving antiplatelet and anticoagulant therapy (higher risk group) compared to patients who do not have a higher risk (normal risk group).

Methods Out of the 43,101 patients documented in the Herniamed Registry who had an incisional hernia repair, 6668 $(15.5 \%)$ were on anticoagulant or antithrombotic therapy or had existing coagulopathy. The implication of that higher risk profile for onset of postoperative bleeding was investigated in multivariable analysis. Hence, other influential variables were identified.

Results The rate of postoperative bleeding in the higher risk group was 3.9\% $(n=261)$ and significantly higher compared to the normal risk group at $1.6 \%(n=564)$ (OR $2.001[1.699 ; 2.356] ; p<0.001)$. Additionally, male gender, use of drains, larger defect size, open incisional hernia repair, lower BMI, and higher ASA score significantly increased the risk of postoperative bleeding. The rate of reoperations due to postoperative bleeding was significantly increased in the higher risk group compared to the normal risk group (2.4 vs. 1.0\%; OR 1.217 [1.071; 1.382]; $p=0.003$ ). Likewise, the postoperative general complication rate $(6.04$ vs. $3.66 \% ; p<0.001)$ as well as the mortality rate $(0.46$ vs. $0.17 \% ; p<0.001)$ were significantly higher in the higher risk group.

Conclusions Patients with anticoagulant or antiplatelet therapy or existing coagulopathy who undergo incisional hernia repair have a significantly higher risk for onset of postoperative bleeding. The risk of bleeding complications and complicationrelated reoperations seems to be lower after laparoscopic intraperitoneal onlay mesh.
\end{abstract}

Keywords Incisional hernia $\cdot$ Bleeding $\cdot$ Postoperative complication $\cdot$ Antithrombotic therapy $\cdot$ Anticoagulant therapy $\cdot$ Coagulopathy

Ralph F. Staerkle and Henry Hoffmann both authors contributed equally to this work.

Electronic supplementary material The online version of this article (https://doi.org/10.1007/s00464-018-6127-y) contains supplementary material, which is available to authorized users.

Ralph F. Staerkle

ralph.staerkle@usb.ch

1 Department of Surgery, Clinic for Visceral Surgery, University Hospital Basel, Spitalstrasse 21, 4031 Basel, Switzerland

2 Department of Surgery and Center for Minimally Invasive Surgery, Academic Teaching Hospital of Charité Medical
Incisional hernias are a common finding following open abdominal surgery, with an incidence depending on size and location of the incision [1,2]. Its incidence ranges from 3 to $20 \%$, with even higher rates following postoperative wound infection [2]. About 50\% of incisional hernias are

School, Vivantes Hospital, Neue Bergstrasse 6, 13585 Berlin, Germany

3 StatConsult GmbH, Halberstädter Straße 40 a, 39112 Magdeburg, Germany

4 Winghofer Medicum Hernia Center, Winghofer Strasse 42, 72108 Rottenburg am Neckar, Germany 
diagnosed within the first 12 months after surgery, but they can also occur several years later, with a subsequent risk of $2 \%$ per year $[2,3]$.

Due to demographic trends, surgical patients may incrementally present with advanced age and associated comorbidities. Antiplatelet or anticoagulant therapy is not uncommon among these patients. Since perioperative management of patients with anticoagulation and antiplatelet medication remains challenging, a careful analysis of the individual patient situation is mandatory [4] to balance the risk of perioperative bleeding and of thromboembolic complications. Hence, in most surgical fields, awareness of postoperative bleeding complications in these patients has been successfully raised [5-7].

Recently, the problem of postoperative bleeding in hernia surgery gained more attention. Omitting antiplatelet medication prior to surgery or discontinuing oral anticoagulation therapy with heparin bridging may help to control the risk of postoperative bleeding after inguinal hernia surgery $[8$, 9]. However, a recent registry-based study showed a fourfold increase in postoperative bleeding following open and endoscopic inguinal hernia repair in patients with antiplatelet medication or anticoagulation [10], highlighting the need for careful perioperative anticoagulation management in hernia patients.

Postoperative hematoma formation after incisional hernia repair has generally been reported as being up to $20 \%$ in both in open and laparoscopic repair [11], requiring interventional procedures or reoperation in some cases. Since open incisional hernia repair may require more extensive dissection compared to laparoscopic repair, the risk of postoperative bleeding complications may even be higher in open cases. However, data on perioperative bleeding complications for patients with anticoagulation, coagulopathy or antiplatelet medication are not available.

Based on the data from the Herniamed Registry [12], this analysis attempts to determine the rate of postoperative bleeding complications following incisional hernia repair and the consecutive rate of bleeding-related reoperation among patients with coagulopathy or receiving antiplatelet and anticoagulant therapy compared with patients who did not have a higher risk profile. Furthermore, it aims to identify other factors, such as patient- and procedure-related factors, influencing the occurrence of bleeding complications.

\section{Materials and methods}

The Herniamed Registry is a multicenter, internet-based hernia registry [12] into which 618 participating hospitals and surgeons in private practice (Herniamed Study Group) in Germany, Austria, and Switzerland (status: July 03, 2017) have entered data on their patients who have undergone elective hernia surgery. All patients signed an informed consent agreeing to participate. As part of the information provided to patients regarding participation in the Herniamed Quality Assurance Study and signing the informed consent declaration, all patients are informed that the treating hospital or medical practice would like to be informed about any problem occurring after the operation and that the patient has the opportunity to attend clinical examination. All postoperative complications occurring up to 30 days after surgery are recorded. On one-year follow-up, postoperative complications are once again reviewed when the general practitioner and patient complete a questionnaire.

The present analysis compares the postoperative data collected for all patients who underwent open incisional hernia repair or laparoscopic IPOM repair between September 1, 2009 and July 03, 2017. Inclusion criteria were a minimum age of 16 years, elective setting of the operation and complete registry database entry. In total, 43,101 patients were enrolled (Fig. 1). Open incisional hernia repair was performed in 29,588 of cases and the laparoscopic technique (IPOM) in 13,513 cases (Table 1).

The patient group at increased risk for onset of postoperative bleeding complications was defined as that comprising patients with either existing coagulopathy (e.g., in the presence of liver cirrhosis), currently receiving platelet aggregation inhibitor therapy or who had discontinued such therapy less than seven days prior to surgery or patients whose quick or international normalized ratio (INR) was not within the normal range during the operation due to treatment with coumarin.

In the Herniamed Registry setting, no additional information, such as the product name of the platelet aggregation inhibitors, exact number of days they had been discontinued or exact INR value, was recorded.

Other potential influence factors investigated were the surgical technique, gender, American Society of Anesthesiologists (ASA) status, age, body mass index (BMI), primary versus recurrent incisional hernia, defect size (W1/W2/W3), and hernia location based on the European Hernia Society (EHS) classification [13], and drainage versus no drainage.

The outcome variable defined was postoperative bleeding within 30 days of operation. Postoperative bleeding is defined as large surface bleeding into the skin surrounding the operation area, hematomas in the operation area, major blood loss from indwelling drains, and reoperations because of postoperative bleeding.

Unadjusted analysis was carried out first to analyze an individual influence variable in respect of a target parameter. The main focus here was on the influence exerted by coagulopathy or antithrombotic therapy on increased bleeding risk. The $\chi^{2}$ test was used for categorical outcome variable. The robust $t$ test (Satterthwaite) was used for continuous outcome variables that followed the normal distribution to 
Fig. 1 Flowchart of patient inclusion

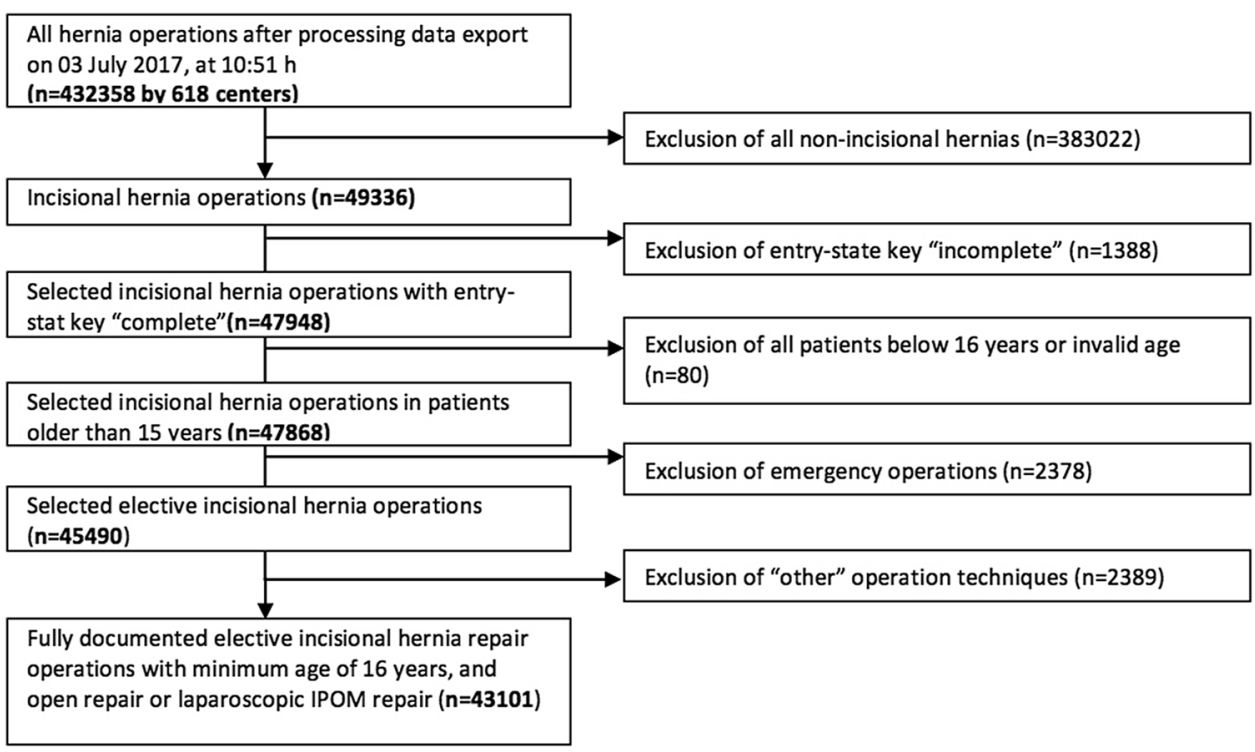

Table 1 Operation techniques

\begin{tabular}{|c|c|c|c|c|c|c|c|}
\hline \multirow[t]{3}{*}{ Access } & \multirow[t]{3}{*}{ Technique } & \multicolumn{4}{|c|}{$\begin{array}{l}\text { Coagulopathy/anticoagulant or } \\
\text { antithrombotic therapy }\end{array}$} & \multirow{2}{*}{\multicolumn{2}{|c|}{ Total }} \\
\hline & & \multicolumn{2}{|l|}{ Yes } & \multicolumn{2}{|l|}{ No } & & \\
\hline & & $N$ & $\%$ & $N$ & $\%$ & $N$ & $\%$ \\
\hline \multirow[t]{5}{*}{ Open } & Onlay & 397 & 0.9 & 1951 & 4.5 & 2348 & 5.4 \\
\hline & Sublay & 2599 & 6.0 & 12,604 & 29.2 & 15,203 & 35.3 \\
\hline & IPOM & 999 & 2.3 & 5311 & 12.3 & 6310 & 14.6 \\
\hline & Component separation & 162 & 0.4 & 823 & 1.9 & 985 & 2.3 \\
\hline & Direct closure & 540 & 1.3 & 4202 & 9.7 & 4742 & 11.0 \\
\hline Laparoscopic & IPOM & 1971 & 4.6 & 11,542 & 26.8 & 13,513 & 31.4 \\
\hline Total & & 6668 & 15.5 & 36,433 & 84.5 & 43,101 & 100.0 \\
\hline
\end{tabular}

Frequency of coagulopathy/antithrombotic therapy for different surgical techniques

IPOM intraperitoneal onlay mesh analyze the influence exerted by coagulopathy or antithrombotic therapy.

A binary logistic regression model was used to study the influence of patient- (demographic) and surgery-related characteristics as well as of an increased bleeding risk associated with existing coagulopathy or antithrombotic therapy on the postoperative secondary bleeding rate, while odds ratio with $95 \%$ confidence interval was based on the Wald test. For influence variables with more than two categories, all pairwise odds ratios were provided. For the continuous influence variable "age," the 10-year odds ratio and for the influence variable "BMI," a five-point odds ratio was given.

In a multivariable model, several variables are analyzed for the effect on an outcome variable. Results are given as odds ratio estimates. These quantify the impact of the single variable on the outcome given that all other variables are constant. This means that estimates are adjusted for all other modeled influences. Thus, a conclusion drawn regarding variables other than the variable of interest is valid and even adjusted for by the remaining variables in the model.

\section{Results}

Out of all patients $(43,101)$ who had an incisional hernia repair, $6,668(15.5 \%)$ were still receiving anticoagulant or effective antiplatelet therapy or had existing coagulopathy. Out of these, 995 (15.0\%) patients had coagulopathy, $n=1.330(20.0 \%)$ a Quick or INR value outside the normal range due to anticoagulation therapy, and $n=4831(72.5 \%)$ of patients had treatment with platelet aggregation inhibitors which had been discontinued less than 7 days prior to surgery or had not at all been discontinued. Some patients had more than one risk factor. 


\section{Unadjusted analysis}

Unadjusted analysis of the relationship between the higher risk group (HRG) (coagulopathy, anticoagulant or antiplatelet therapy) and the normal risk group (NRG) showed that there were highly significant differences between the two groups regarding patient- and procedure-related characteristics. Patients in the HRG who were significantly older $(68.8 \pm 10.7$ vs. $60.1 \pm 14.0 ; p<0.001)$ and had a (just slightly but) significantly lower BMI $(29.3 \pm 5.4$ vs. $29.6 \pm 6.1, p<0.001$ ), were predominantly male, had higher ASA scores, more open repairs, larger defect size, and more intraoperative drains (Table 2).

As shown in unadjusted analyses in Table 3, the overall postoperative surgical complication rate in the HRG was significantly higher compared to the NRG (12.0 vs. $7.6 \%$, $p<0.001)$. Bowel injury, ileus, bleeding, seroma, wound healing disorders and deep infections were significantly

Table 2 Demographics and surgery-related parameters

\begin{tabular}{|c|c|c|c|c|c|}
\hline & \multicolumn{4}{|c|}{$\begin{array}{l}\text { Coagulopathy/anticoagulant or } \\
\text { antithrombotic therapy }\end{array}$} & \multirow[t]{3}{*}{$p$} \\
\hline & \multicolumn{2}{|l|}{ Yes } & \multicolumn{2}{|l|}{ No } & \\
\hline & $n$ & $\%$ & $n$ & $\%$ & \\
\hline \multicolumn{6}{|l|}{ Operation } \\
\hline Laparoscopic & 1971 & 29.56 & 11,542 & 31.68 & \multirow[t]{2}{*}{$<0.001$} \\
\hline Open & 4697 & 70.44 & 24,891 & 68.32 & \\
\hline \multicolumn{6}{|l|}{ Sex } \\
\hline Male & 4021 & 60.30 & 17,533 & 48.12 & \multirow[t]{2}{*}{$<0.001$} \\
\hline Female & 2647 & 39.70 & 18,900 & 51.88 & \\
\hline \multicolumn{6}{|l|}{ ASA score } \\
\hline I & 95 & 1.42 & 5057 & 13.88 & \multirow[t]{3}{*}{$<0.001$} \\
\hline II & 2215 & 33.22 & 21,641 & 59.40 & \\
\hline III/IV & 4358 & 65.36 & 9735 & 26.72 & \\
\hline \multicolumn{6}{|l|}{ Recurrence } \\
\hline Yes & 1361 & 20.41 & 7776 & 21.34 & \multirow[t]{2}{*}{0.087} \\
\hline No & 5307 & 79.59 & 28,657 & 78.66 & \\
\hline \multicolumn{6}{|l|}{ EHS classification } \\
\hline Combination & 567 & 8.50 & 3260 & 8.95 & \multirow[t]{3}{*}{0.406} \\
\hline Lateral & 1094 & 16.41 & 5834 & 16.01 & \\
\hline Medial & 5007 & 75.09 & 27,339 & 75.04 & \\
\hline \multicolumn{6}{|l|}{ Defect size } \\
\hline $\mathrm{W} 1(<4 \mathrm{~cm})$ & 1953 & 29.29 & 13,737 & 37.70 & \multirow[t]{3}{*}{$<0.001$} \\
\hline $\mathrm{W} 2(\geq 4-10 \mathrm{~cm})$ & 3301 & 49.51 & 16,546 & 45.41 & \\
\hline $\mathrm{W} 3(\geq 10 \mathrm{~cm})$ & 1414 & 21.21 & 6150 & 16.88 & \\
\hline \multicolumn{6}{|l|}{ Drainage } \\
\hline Yes & 3959 & 59.37 & 18,957 & 52.03 & \multirow[t]{2}{*}{$<0.001$} \\
\hline No & 2709 & 40.63 & 17,476 & 47.97 & \\
\hline
\end{tabular}

Unadjusted analysis for demographics and surgery-related parameters ASA American Society of Anesthesiologists, EHS European Hernia Society
Table 3 Postoperative surgical complications following incisional hernia repair

Coagulopathy/anticoagulant or antithrombotic $\quad p$ value therapy

\begin{tabular}{llll}
\hline Yes & & No & \\
$n$ & $\%$ & $\%$
\end{tabular}

\begin{tabular}{|c|c|c|c|c|c|}
\hline \multicolumn{6}{|c|}{ Postoperative complications } \\
\hline Yes & 797 & 11.95 & 2762 & 7.58 & \multirow[t]{2}{*}{$<0.001$} \\
\hline No & 5871 & 88.05 & 33,671 & 92.42 & \\
\hline \multicolumn{6}{|c|}{ Bowel injury } \\
\hline Yes & 51 & 0.76 & 153 & 0.42 & \multirow[t]{2}{*}{$<0.001$} \\
\hline No & 6617 & 99.24 & 36,280 & 99.58 & \\
\hline \multicolumn{6}{|l|}{ Ileus } \\
\hline Yes & 66 & 0.99 & 213 & 0.58 & \multirow[t]{2}{*}{$<0.001$} \\
\hline No & 6602 & 99.01 & 36,220 & 99.42 & \\
\hline \multicolumn{6}{|c|}{ Deep infection } \\
\hline Yes & 101 & 1.51 & 438 & 1.20 & \multirow[t]{2}{*}{0.035} \\
\hline No & 6567 & 98.49 & 35,995 & 98.80 & \\
\hline \multicolumn{6}{|c|}{ Bleeding } \\
\hline Yes & 261 & 3.91 & 564 & 1.55 & \multirow[t]{2}{*}{$<0.001$} \\
\hline No & 6407 & 96.09 & 35,869 & 98.45 & \\
\hline \multicolumn{6}{|c|}{ Seroma } \\
\hline Yes & 303 & 4.54 & 1272 & 3.49 & \multirow[t]{2}{*}{$<0.001$} \\
\hline No & 6365 & 95.46 & 35,161 & 96.51 & \\
\hline \multicolumn{6}{|c|}{ Wound healing disorder } \\
\hline Yes & 200 & 3.00 & 734 & 2.01 & \multirow[t]{2}{*}{$<0.001$} \\
\hline No & 6468 & 97.00 & 35,699 & 97.99 & \\
\hline
\end{tabular}

more frequent in the HRG. Postoperative bleeding occurred significantly more frequently in the HRG (3.9 vs. $1.6 \%$, $p<0.001$ ) (Table 3).

The overall complication-related reoperation rate in the HRG was significantly higher compared to the NRG (5.7 vs. $3.6 \% ; p<0.001)$. The postoperative bleeding-related reoperation rate was also significantly higher in the HRG (2.4 vs. $1.0 \% ; p<0.001$ ) (Table 4).

No significant difference was found between the intraoperative complication rates (HRG $2.25 \%$ vs. NRG $1.92 \%$; $p=0.074)$. However, significant differences were also identified in the postoperative general complication rates to the disadvantage of the HRG (6.04 vs. $3.66 \%$; $p<0.001)$. Likewise, the mortality rate in the HRG was significantly higher (0.46 vs. $0.17 \% ; p<0.001)$.

\section{Differences in the subgroups: unadjusted analysis}

An additional analysis was performed to identify whether there were any differences in the postoperative bleeding rates and in the bleeding-related reoperation rates between the coagulopathy, anticoagulant therapy and antiplatelet therapy subgroups. To that effect, the groups with only one 
Table 4 Postoperative complication-related reoperation rates

Coagulopathy/anticoagulant or antithrombotic $p$ therapy

\begin{tabular}{llll}
\hline Yes & & No & \\
$n$ & $\%$ & & $\%$
\end{tabular}

Postoperative bleeding

\begin{tabular}{|c|c|c|c|c|c|}
\hline Yes & 261 & 3.91 & 564 & 1.55 & $<0.001$ \\
\hline No & 6407 & 96.09 & 35,869 & 98.45 & \\
\hline \multicolumn{6}{|c|}{ Complication-related reoperation rate } \\
\hline Yes & 377 & 5.65 & 1303 & 3.58 & \multirow[t]{2}{*}{$<0.001$} \\
\hline No & 6291 & 94.35 & 35,130 & 96.42 & \\
\hline \multicolumn{6}{|c|}{ leeding-related reoperation rate } \\
\hline Yes & 163 & 2.44 & 356 & 0.98 & \multirow[t]{2}{*}{$<0.001$} \\
\hline No & 6505 & 97.56 & 36,077 & 99.02 & \\
\hline
\end{tabular}

Unadjusted analysis for postoperative bleeding and reoperation rates (overall and bleeding related)

risk factor were compared with each other (total: $n=6210$, coagulopathy: $n=664$, antiplatelet therapy: $n=4506$, anticoagulant therapy: $n=1040$ ). Significant differences were found in the postoperative bleeding rates of $5.3 \%$ for the coagulopathy subgroup, $7.5 \%$ for the anticoagulant therapy subgroup, and $2.5 \%$ for the antiplatelet therapy subgroup $(p<0.001)$. Accordingly, significant differences were also detected in the bleeding-related reoperation rates (3.8 vs. 4.8 vs. $1.4 \% ; p<0.001)$. As such, the risk of both postoperative bleeding and bleeding-related reoperation was lowest in the antiplatelet therapy patient group.

\section{Multivariable analysis of postoperative bleeding}

The results of the multivariable analysis of postoperative bleeding are summarized in Table 5 (model fit $p<0.001$ ). The risk of postoperative bleeding in open and laparoscopic cases is significantly higher in patients with coagulopathy, anticoagulant or antiplatelet therapy $(p<0.001)$ with an odds ratio of 2.001 [1.699; 2.356]. There were significantly more cases of postoperative bleeding in the group with drains (OR $2.016[1.653 ; 2.457] ; p<0.001$ ), in male patients (OR 1.525 $[1.319 ; 1.763] ; p<0.001$ ), in larger defects (e.g., W3 vs. W1: OR 1.683 [1.360; 2.083]; $p<0.001)$, and after open repair (OR 1.644 [1.317; 2.052]; $p<0.001)$. In the higher ASA categories (ASA III/IV vs. II: OR 1.244 [1.064; $1.455] ; p=0.006$; ASA III/IV vs. I: OR 1.524 [1.114; 2.084]; $p=0.008$ ), the risk of postoperative bleeding was increased as well. In contrast, the risk of postoperative bleeding decreases with higher BMI (five-point BMI: $O R$ 0.895 [0.837; 0.956]; $p<0.001$ ).

\section{Multivariable analysis of reoperations due to postoperative bleeding}

The results of the multivariable analysis of reoperations due to postoperative bleeding are summarized in Table 6 (model fit $p<0.001)$. The use of drains (OR 2.714 [2.082; 3.539]; $p<0.001)$, coagulopathy, antiplatelet or anticoagulant therapy (OR 1.944 [1.584; 2.387]; $p<0.001$ ), male gender (OR 1.629 [1.356; 1.957]; $p<0.001$ ), larger defect size (W3 vs. W1: OR 1.745 [1.330; 2.291]; $p<0.001 \mathrm{~W} 2$ vs. W1: OR 1.535 [1.209; 1.947]; $p<0.001$ ),

Table 5 Multivariable analysis of postoperative bleeding following open and laparoscopic incisional hernia repair

\begin{tabular}{|c|c|c|c|c|c|c|}
\hline \multirow{2}{*}{$\begin{array}{l}\text { Parameter } \\
\text { Coagulopathy, anticoagulant, or } \\
\text { antithrombotic therapy }\end{array}$} & \multirow{2}{*}{$\frac{p \text { value }}{<0.001}$} & \multirow{2}{*}{$\frac{\text { Category }}{\text { Yes vs. no }}$} & \multirow{2}{*}{$\frac{\text { Paired } p \text { value }}{<0.001}$} & \multirow{2}{*}{$\frac{\mathrm{OR}}{2.001}$} & \multicolumn{2}{|c|}{$[95 \% \mathrm{CI}]$} \\
\hline & & & & & 1.699 & 2.356 \\
\hline Drainage & $<0.001$ & Yes vs. no & $<0.001$ & 2.016 & 1.653 & 2.457 \\
\hline Gender & $<0.001$ & Male vs. female & $<0.001$ & 1.525 & 1.319 & 1.763 \\
\hline \multirow[t]{3}{*}{ Defect size } & \multirow[t]{3}{*}{$<0.001$} & $\mathrm{~W} 3(\geq 10 \mathrm{~cm})$ vs. W2 $(\geq 4-10 \mathrm{~cm})$ & 0.053 & 1.180 & 0.998 & 1.396 \\
\hline & & $\mathrm{W} 3(\geq 10 \mathrm{~cm})$ vs. W1 $(<4 \mathrm{~cm})$ & $<0.001$ & 1.683 & 1.360 & 2.083 \\
\hline & & $\mathrm{W} 2(\geq 4-10 \mathrm{~cm})$ vs. W1 $(<4 \mathrm{~cm})$ & $<0.001$ & 1.426 & 1.185 & 1.717 \\
\hline Operation technique & $<0.001$ & Open vs. laparoscopic & $<0.001$ & 1.644 & 1.317 & 2.052 \\
\hline BMI [5-point OR] & $<0.001$ & & & 0.895 & 0.837 & 0.956 \\
\hline \multirow[t]{3}{*}{ ASA } & \multirow[t]{3}{*}{0.005} & III/IV vs. II & 0.006 & 1.244 & 1.064 & 1.455 \\
\hline & & III/IV vs. I & 0.008 & 1.524 & 1.114 & 2.084 \\
\hline & & II vs. I & 0.177 & 1.225 & 0.912 & 1.644 \\
\hline \multirow[t]{3}{*}{ EHS classification } & \multirow[t]{3}{*}{0.057} & Medial vs. combined & 0.413 & 1.108 & 0.867 & 1.417 \\
\hline & & Medial vs. lateral & 0.020 & 1.283 & 1.040 & 1.583 \\
\hline & & Combined vs. lateral & 0.345 & 1.158 & 0.854 & 1.570 \\
\hline Age [10-year OR] & 0.282 & & & 1.033 & 0.973 & 1.097 \\
\hline Recurrences & 0.645 & Yes vs. no & 0.645 & 1.041 & 0.878 & 1.233 \\
\hline
\end{tabular}


Table 6 Multivariable analysis of reoperations due to postoperative secondary bleeding

\begin{tabular}{|c|c|c|c|c|c|c|}
\hline \multirow{2}{*}{$\frac{\text { Parameter }}{\text { Drainage }}$} & \multirow{2}{*}{$\frac{p \text { value }}{<0.001}$} & \multirow{2}{*}{$\frac{\text { Category }}{\text { Yes vs. no }}$} & \multirow{2}{*}{$\begin{array}{l}\text { Paired } p \text { value } \\
<0.001\end{array}$} & \multirow{2}{*}{$\frac{\mathrm{OR}}{2.714}$} & \multicolumn{2}{|c|}{$95 \% \mathrm{CI}$} \\
\hline & & & & & 2.082 & 3.539 \\
\hline $\begin{array}{l}\text { Coagulopathy, } \\
\text { antithrombotic } \\
\text { therapy }\end{array}$ & $<0.001$ & Yes vs. no & $<0.001$ & 1.944 & 1.584 & 2.387 \\
\hline Gender & $<0.001$ & Male vs. female & $<0.001$ & 1.629 & 1.356 & 1.957 \\
\hline BMI [5-point OR] & $<0.001$ & & & 0.817 & 0.750 & 0.890 \\
\hline \multirow[t]{3}{*}{ Defect size } & \multirow[t]{3}{*}{$<0.001$} & $\mathrm{~W} 3(\geq 10 \mathrm{~cm})$ vs. W2 $(\geq 4-10 \mathrm{~cm})$ & 0.226 & 1.137 & 0.923 & 1.401 \\
\hline & & $\mathrm{W} 3(\geq 10 \mathrm{~cm})$ vs. W1 $(<4 \mathrm{~cm})$ & $<0.001$ & 1.745 & 1.330 & 2.291 \\
\hline & & $\mathrm{W} 2(\geq 4-10 \mathrm{~cm})$ vs. W1 $(<4 \mathrm{~cm})$ & $<0.001$ & 1.535 & 1.209 & 1.947 \\
\hline Operation technique & 0.007 & Open vs. laparoscopic & 0.007 & 1.482 & 1.114 & 1.970 \\
\hline \multirow[t]{3}{*}{ ASA } & \multirow[t]{3}{*}{0.010} & III/IV vs. II & 0.006 & 1.320 & 1.085 & 1.606 \\
\hline & & III/IV vs. I & 0.030 & 1.531 & 1.043 & 2.247 \\
\hline & & II vs. I & 0.420 & 1.160 & 0.809 & 1.663 \\
\hline \multirow[t]{3}{*}{ EHS classification } & \multirow[t]{3}{*}{0.065} & Medial vs. combined & 0.393 & 1.145 & 0.840 & 1.560 \\
\hline & & Medial vs. lateral & 0.024 & 1.365 & 1.042 & 1.789 \\
\hline & & Combined vs. Lateral & 0.373 & 1.193 & 0.809 & 1.759 \\
\hline Recurrence & 0.222 & Yes vs. no & 0.222 & 1.139 & 0.925 & 1.403 \\
\hline Age [10-year OR] & 0.777 & & & 0.989 & 0.919 & 1.065 \\
\hline
\end{tabular}

open incisional hernia repair (OR 1.482 [1.114; 1.970]; $p=0.007$ ), and higher ASA scores (ASA III/IV vs. II: OR 1.320 [1.085; 1.606]; $p=0.006$ ASA III/IV vs. I: OR 1.531 $[1.043 ; 2.247] ; p=0.030)$ increased the risk of reoperation due to postoperative bleeding significantly. In contrast, the risk of reoperation due to postoperative bleeding decreases with higher BMI (five-point BMI OR 0.817 [0.750; 0.890]; $p<0.001$ ) (Table 6).

\section{Multivariable analysis of reoperations due to postoperative complications}

The results of the multivariable analysis of reoperations due to postoperative complications are summarized in Table 7 (model fit $p<0.001$ ). The risk of reoperation is significantly associated with larger defects (W3 vs. W2: OR 1.611 [1.439; 1.803]; $p<0.001 ; \mathrm{W} 3$ vs. W1: OR 2.690 [2.306; 3.139]; $p<0.001 ; \mathrm{W} 2$ vs. W1: OR 1.670 [1.449;
Table 7 Multivariable analysis of reoperations due to postoperative complications

\begin{tabular}{lllrrrr}
\hline Parameter & $p$ value & Category & Paired $p$ value & OR & \multicolumn{2}{l}{$95 \%$ CI } \\
\hline Defect size & $<0.001$ & W3 $(\geq 10 \mathrm{~cm})$ vs. W2 $(\geq 4-10 \mathrm{~cm})$ & $<0.001$ & 1.611 & 1.439 & 1.803 \\
& & W3 $(\geq 10 \mathrm{~cm})$ vs. W1 $(<4 \mathrm{~cm})$ & $<0.001$ & 2.690 & 2.306 & 3.139 \\
& & W2 $(\geq 4-10 \mathrm{~cm})$ vs. W1 $(<4 \mathrm{~cm})$ & $<0.001$ & 1.670 & 1.449 & 1.925 \\
Drainage & $<0.001$ & Yes vs. no & $<0.001$ & 1.986 & 1.720 & 2.292 \\
ASA & $<0.001$ & III/IV vs. II & $<0.001$ & 1.525 & 1.366 & 1.703 \\
& & III/IV vs. I & $<0.001$ & 1.636 & 1.318 & 2.032 \\
& & II vs. I & 0.503 & 1.073 & 0.873 & 1.317 \\
Operation technique & $<0.001$ & Open vs. laparoscopic & $<0.001$ & 1.618 & 1.385 & 1.892 \\
Recurrence & $<0.001$ & Yes vs. no & $<0.001$ & 1.252 & 1.117 & 1.403 \\
EHS classification & $<0.001$ & Medial vs. combined & 0.764 & 1.026 & 0.869 & 1.210 \\
& & Medial vs. lateral & $<0.001$ & 1.394 & 1.192 & 1.629 \\
& & Combined vs. Lateral & 0.005 & 1.359 & 1.097 & 1.682 \\
Coagulopathy, & 0.003 & Yes vs. no & 0.003 & 1.217 & 1.071 & 1.382 \\
antithrombotic & & & & & & \\
therapy & & & & 1.065 & 1.021 & 1.110 \\
BMI [5-point OR] & 0.003 & & & 1.032 & 0.989 & 1.076 \\
Alter [10-year OR] & 0.150 & & 0.202 & 1.068 & 0.965 & 1.181 \\
Sex & 0.202 & Male vs. female & &
\end{tabular}


1.925]; $p<0.001$ ), with the use of drains (OR 1.986 [1.720; 2.292]; $p<0.001$ ), higher ASA scores (ASA III/IV vs. II: OR $1.525[1.366 ; 1.703] ; \mathrm{p}<0.001 ;$ ASA III/IV vs. I: OR 1.636 [1.318; 2.032]; $p<0.001$ ), open surgery (OR 1.618 $[1.385 ; 1.892] ; p<0.001$ ), recurrent incisional hernias (OR 1.252 [1.117; 1.403$] ; p<0.001)$, and EHS classification $(p<0.001)$ in terms of medial compared to lateral incisional hernias (OR 1.394 [1.192; 1.629]; $p<0.001$ ), and combined compared to lateral incisional hernias (OR 1.359 [1.097; 1.682 ]; $p=0.005)$. Existing coagulopathy, anticoagulant or antiplatelet therapy (OR $1.217[1.071 ; 1.382] ; p=0.003$ ) and patients with a higher BMI (five-point BMI: OR 1.065 $[1.021 ; 1.110] ; p=0.003)$ increase the risk of reoperation (Table 7).

\section{Discussion}

Our study showed that patients undergoing incisional hernia repair with existing coagulopathy, anticoagulant or antiplatelet therapy have a significantly higher postoperative surgical complication rate, postoperative bleeding rate, postoperative general complication rate, and mortality compared to patients without these pre-existing conditions. The risk of bleeding or of bleeding-related reoperation was significantly lower for the antiplatelet therapy subgroup than for the coagulopathy and anticoagulant therapy subgroups. Comparing open and laparoscopic IPOM approach, the postoperative bleeding rate was higher in open repair compared to laparoscopic IPOM repair, with significantly higher rates of postoperative bleeding in the HRG. Accordingly, the overall reoperation rate and bleeding-related reoperation rate were both significantly higher after open repair compared to laparoscopic repair. Since the registry does not record any information on this, the extent of dissection in laparoscopic IPOM cases is unknown. In particular, it remains unclear whether all connective and fatty tissues were removed from the "landing zone" in the region of the round ligament of liver (hepatic teres ligament) and the hepatic falciform ligament.

Another inherent weakness of a registry study is the fact that outcome criteria for bleeding seem very subjective. Bleeding on the skin or the volume of blood in the drain is not specified, nor is the person reporting this identified.

The multivariable analysis revealed other factors, which are significantly associated with an increased risk of postoperative bleeding, such as the use of drains, male gender, larger hernia defect size, and higher ASA score. Although there is a higher risk of bleeding in large defects, multivariable analysis shows an additional significant effect of the technique.

Furthermore, the reoperation rate due to bleeding-related complications as well as the reoperation rate due to other complications was significantly higher in the HRG compared to the NRG.

Postoperative bleeding and consecutive hematomas are bothersome for the patients and have a strong clinical impact requiring interventional or operative treatment [14]. Postoperative bleeding is a typical adverse event occurring after surgery [15]. Regarding inguinal hernia surgery alone, postoperative bleeding is the most frequent adverse event $[16,17]$. A recent registry-based analysis of 82,911 patients undergoing open or endoscopic [transabdominal preperitoneal patch plasty (TAPP), total extraperitoneal patch plasty (TEP)] inguinal hernia repair showed a fourfold higher risk for onset of postoperative bleeding in patients with existing anticoagulation or antithrombotic therapy [10]. Surprisingly, the endoscopic procedures (TAPP, TEP) showed lower postoperative bleeding rates compared to open inguinal hernia repair, although the endoscopic techniques were deemed as being more likely to cause postoperative bleeding due to their more extensive tissue dissection. Additionally, larger hernia defect size, male gender, higher ASA score, and recurrent operation were identified as significant risk factors for postoperative bleeding in the registry population [10]. However, data on the risk of postoperative bleeding among patients undergoing incisional hernia repair are rare. Usually, incisional hernia repair is an elective procedure with carefully prepared patients. Since incisional hernias can present with larger defect sizes posing additional challenges, such as loss of domain, previous abdominal surgery or intraabdominal adhesions, prevention of postoperative bleeding necessitating reoperation seems to be of utmost importance. This is even more important in view of the fact that postoperative bleeding complications are deemed to be risk factors for recurrence after laparoscopic ventral hernia repair [18].

A recent study using a propensity score analysis of 486 consecutive patients undergoing incisional hernia repair revealed anticoagulation as a pre-existing condition frequently found in the risk group for postoperative bleeding, developing hematomas in $9.9 \%$ of open cases and 3.3\% of laparoscopic IPOM cases [19]. In our study, however, we demonstrated that postoperative bleeding occurred in up to $3.9 \%$ of patients in the HRG of patients with coagulopathy, anticoagulant or antithrombotic therapy, leading to a significantly higher bleeding-related reoperation rate of $2.44 \%$ $(n=163)$ in the HRG compared to the NRG $(0.98 \%)$. This demonstrates that coagulopathy, anticoagulant or antithrombotic therapy is an evident risk factor for postoperative bleeding requiring reoperation in a reasonable number of patients, with known unfavorable consequences such as prolonged hospital stays and increased direct and indirect healthcare costs.

The type of surgical approach in hernia surgery and its impact on postoperative complications are an ongoing 
debate. A recent analysis revealed substantial variation among hernia experts regarding decision-making in treatment strategies for incisional hernia patients [20], highlighting the difficulties in selecting the most appropriate surgical technique for the patient. Thus, it must be assumed that to date the choice of surgical technique in incisional hernia repair has been influenced more by the hernia parameters than by individual patient factors. Our study results demonstrate that the choice of surgical technique has significant impact on the postoperative outcome.

Apart from the surgical technique, a larger defect size, male gender, and higher ASA classification, intraoperative drains were identified as further risk factors for occurrence of postoperative bleeding. However, intraoperative drains must be viewed as a false-positive risk factor since drains themselves are unlikely to cause postoperative bleeding. It can be assumed that most surgeons usually place drains when they suspect possible postoperative bleeding, such as in high-risk patients.

Our data show that patients with abnormal INR or inadequate discontinuation of their antiplatelet or anticoagulation therapy undergoing incisional hernia repair are a high-risk population for onset of postoperative bleeding. Surgery for patients with these pre-existing conditions should be postponed or patients should be assigned to laparoscopic surgery when technically feasible and surgically meaningful, since laparoscopic IPOM repair has been shown to provide much more favorable outcomes compared to open repair. However, the advantages of the laparoscopic IPOM method should be carefully balanced against the described, technically inherent complications and the concerns arising from the emerging discussion of IPOM-related mesh complications in the abdominal cavity [21-23].

\section{Compliance with ethical standards}

Disclosures F Köckerling-Grants to fund the Herniamed Registry from Johnson \& Johnson, Norderstedt; pfm medical, Cologne; Dahlhausen, Cologne; B Braun, Tuttlingen; MenkeMed, Munich and Bard, Karlsruhe. D Adolf-fees for statistical support from Herniamed gGmbH, Berlin. RF Staerkle, H Hoffmann, R Bittner, and P Kirchhoff have no conflicts of interest or financial ties to disclose.

Open Access This article is distributed under the terms of the Creative Commons Attribution 4.0 International License (http://creativeco mmons.org/licenses/by/4.0/), which permits unrestricted use, distribution, and reproduction in any medium, provided you give appropriate credit to the original author(s) and the source, provide a link to the Creative Commons license, and indicate if changes were made.

\section{References}

1. Kingsnorth A, LeBlanc K (2003) Hernias: inguinal and incisional. Lancet 362(9395):1561-1571. https://doi.org/10.1016/S0140 $-6736(03) 14746-0$

2. Mudge M, Hughes LE (1985) Incisional hernia: a 10 year prospective study of incidence and attitudes. Br J Surg 72(1):70-71

3. Bucknall TE, Cox PJ, Ellis H (1982) Burst abdomen and incisional hernia: a prospective study of 1129 major laparotomies. Br Med J 284(6320):931-933

4. Schlitt A, Jambor C, Spannagl M, Gogarten W, Schilling T, Zwissler B (2013) The perioperative management of treatment with anticoagulants and platelet aggregation inhibitors. Dtsch Arztebl Int 110(31-32):525-532. https://doi.org/10.3238/arzte bl.2013.0525

5. Manchikanti L, Falco FJ, Benyamin RM, Caraway DL, Kaye AD, Helm S 2nd, Wargo BW, Hansen H, Parr AT, Singh V, Swicegood JR, Smith HS, Schultz DM, Malla Y, Hirsch JA (2013) Assessment of bleeding risk of interventional techniques: a best evidence synthesis of practice patterns and perioperative management of anticoagulant and antithrombotic therapy. Pain Physician 16 (2 Suppl):261-318

6. Oltmann SC, Alhefdhi AY, Rajaei MH, Schneider DF, Sippel RS, Chen H (2016) Antiplatelet and anticoagulant medications significantly increase the risk of postoperative hematoma: review of over 4500 thyroid and parathyroid procedures. Ann Surg Oncol 23(9):2874-2882. https://doi.org/10.1245/s1043 4-016-5241-0

7. Wolf AM, Pucci MJ, Gabale SD, McIntyre CA, Irizarry AM, Kennedy EP, Rosato EL, Lavu H, Winter JM, Yeo CJ (2014) Safety of perioperative aspirin therapy in pancreatic operations. Surgery 155(1):39-46. https://doi.org/10.1016/j.surg.2013.05.031

8. Bombuy E, Mans E, Hugue A, Plensa E, Rodriguez L, Prats M, Sunol X (2009) Elective inguinal hernioplasty in patients on chronic anticoagulation therapy: management and outcome. Cir Esp 86(1):38-42. https://doi.org/10.1016/j.ciresp.2009.02.016

9. Sanders DL, Shahid MK, Ahlijah B, Raitt JE, Kingsnorth AN (2008) Inguinal hernia repair in the anticoagulated patient: a retrospective analysis. Hernia 12(6):589-592. https://doi.org/10.1007/ s10029-008-0405-x (discussion 667-588)

10. Köckerling F, Roessing C, Adolf D, Schug-Pass C, Jacob D (2016) Has endoscopic (TEP, TAPP) or open inguinal hernia repair a higher risk of bleeding in patients with coagulopathy or antithrombotic therapy? Data from the Herniamed Registry. Surg Endosc 30(5):2073-2081. https://doi.org/10.1007/s00464-015-4456-7

11. Sauerland S, Walgenbach M, Habermalz B, Seiler CM, Miserez M (2011) Laparoscopic versus open surgical techniques for ventral or incisional hernia repair. Cochrane Database Syst Rev (3):CD007781. https://doi.org/10.1002/14651858.CD007781. pub2

12. Stechemesser B, Jacob DA, Schug-Pass C, Köckerling F (2012) Herniamed: an internet-based registry for outcome research in hernia surgery. Hernia 16(3):269-276. https://doi.org/10.1007/ s10029-012-0908-3

13. Muysoms FE, Miserez M, Berrevoet F, Campanelli G, Champault GG, Chelala E, Dietz UA, Eker HH, El Nakadi I, Hauters P, Hidalgo Pascual M, Hoeferlin A, Klinge U, Montgomery A, Simmermacher RK, Simons MP, Smietanski M, Sommeling C, Tollens T, Vierendeels T, Kingsnorth A (2009) Classification of primary and incisional abdominal wall hernias. Hernia 13(4):407414. https://doi.org/10.1007/s10029-009-0518-x

14. McCormick JT, Simmang CL (2006) Reoperation following minimally invasive surgery: are the "rules" different? Clin Colon Rectal Surg 19(4):217-222. https://doi.org/10.1055/s-2006-956443 
15. Calland JF, Adams RB, Benjamin DK Jr, O'Connor MJ, Chandrasekhara V, Guerlain S, Jones RS (2002) Thirty-day postoperative death rate at an academic medical center. Ann Surg 235(5):690-696 (discussion 696-698)

16. Köckerling F, Bittner R, Jacob DA, Seidelmann L, Keller T, Adolf D, Kraft B, Kuthe A (2015) TEP versus TAPP: comparison of the perioperative outcome in 17,587 patients with a primary unilateral inguinal hernia. Surg Endosc 29(12):3750-3760. https://doi. org/10.1007/s00464-015-4150-9

17. Weyhe D, Tabriz N, Sahlmann B (2017) Risk factors for perioperative complications in inguinal hernia repair: a systematic review. Innov Surg Sci 2(2):47-52

18. Mercoli H, Tzedakis S, D’Urso A, Nedelcu M, Memeo R, Meyer N, Vix M, Perretta S, Mutter D (2017) Postoperative complications as an independent risk factor for recurrence after laparoscopic ventral hernia repair: a prospective study of 417 patients with long-term follow-up. Surg Endosc 31(3):1469-1477. https ://doi.org/10.1007/s00464-016-5140-2

19. Dietz UA, Fleischhacker A, Menzel S, Klinge U, Jurowich C, Haas K, Heuschmann P, Germer CT, Wiegering A (2017) Risk-adjusted procedure tailoring leads to uniformly low complication rates in ventral and incisional hernia repair: a propensity score analysis and internal validation of classification criteria. Hernia 21(4):569 582. https://doi.org/10.1007/s10029-017-1622-y

20. Kokotovic D, Gogenur I, Helgstrand F (2017) Substantial variation among hernia experts in the decision for treatment of patients with incisional hernia: a descriptive study on agreement. Hernia 21(2):271-278. https://doi.org/10.1007/s10029-016-1562-y

21. Jamry A, Jalynski M, Piskorz L, Brocki M (2013) Assessment of adhesion formation after laparoscopic intraperitoneal implantation of Dynamesh IPOM mesh. Arch Med Sci 9(3):487-492. https:// doi.org/10.5114/aoms.2013.35345

22. Meyer R, Hage A, Zimmermann M, Bruch HP, Keck T, Hoffmann M, Schloricke E (2015) Is laparoscopic treatment of incisional and recurrent hernias associated with an increased risk for complications? Int J Surg 19:121-127. https://doi.org/10.1016/j. ijsu.2015.05.046

23. Yang GPC (2017) From intraperitoneal onlay mesh repair to preperitoneal onlay mesh repair. Asian J Endosc Surg 10(2):119-127. https://doi.org/10.1111/ases.12388 